\title{
ESTUDO DA OXIDAÇÃO DE OXITETRACICLINA PELO PROCESSO FENTON: VERIFICAÇÃO DA INFLUÊNCIA DA TEMPERATURA E CONCENTRAÇÃO INICIAL DO FÁRMACO
}

\author{
VINICIOS TORREZAN ALVES, MAURI SÉRGIO ALVES PALMA \\ Universidade de São Paulo/Faculdade de ciências farmacêuticas \\ Vinicios.alves@usp.br
}

\section{Resumo}

Neste trabalho foi estudada a degradação da oxitetraciclina pelo processo Fenton. A concentração residual do antibiótico foi determinada por método espectrofotométrico. Testou-se uma solução aquosa de oxitetraciclina (100 ppm), solução de $\mathrm{Fe}^{2+}(5 \mathrm{ppm})$ e peróxido de hidrogênio (100 ppm). Nesta etapa do estudo foram testadas diferentes temperaturas e concentrações inciais do fármaco à ser degradado a fim de verificar a influência sobre a concentração residual de oxitetraciclina.

\section{Introdução}

O uso de antibióticos tem aumentado significativamente ao longo dos anos, este aumento gera um reflexo nos efluentes que recebem dejetos animais e humanos, visto que de $25 \%$ até $75 \%$ do antibiótico pode ser eliminado sem metabolização (Watkinson et. al., 2009). Com o acúmulo de fármacos na natureza, ocorre uma seleção de bactérias resistentes aos antibióticos. Assim, surge a necessidade de estudar processos de degradação de tais moléculas por processos oxidativos avançados (POA), dentre os quais se inclui o processo Fenton que degrada tais moléculas, resultando normalmente em água, $\mathrm{CO}_{2} \mathrm{e}$ outros sais inorgânicos. A oxitetraciclina (OTC) é um antibiótico da classe das tetraciclinas (Borghi, 2013), apresenta ação de largo espectro e aplicável a uma ampla gama de bactérias gram-positivas e gram-negativas. A fórmula estrutural da oxitetraciclina é mostrada na Figura 1. Como o trabalho se baseia no estudo do tratamento de efluentes contaminados com a OTC, surgiu a necessidade de estudar a influência de ânions comuns em ambientes naturais, que podem reduzir a eficiência do processo. Os ânions testados no processo Fenton até o momento foram fosfato, cloreto e sulfato. Os experimentos foram realizados inicialmente para determinação da condição ideal de oxidação, as variáveis estudadas foram as concentrações de íons ferroso e de peróxido de hidrogênio, a fim de determinar a condição ótima da degradação. Após a determinação desta condição, iniciou-se o estudo da influência de ânions, possivelmente presentes em efluentes industriais, assim, variou-se a concentração dos ânions com o objetivo de determinar se havia interferência positiva ou negativa na oxidação do fármaco.<smiles>CN(C)C1C(O)=C(C(N)=O)C(=O)C2(O)C(O)=C3C(=O)c4c(O)cccc4[C@@](C)(O)C3(C)C(O)C12</smiles>

Figura 1 - Fórmula estrutural da oxitetraciclina.

O processo Fenton é um Processo Oxidativo Avançado (POA) de fácil uso e baixo custo, portanto é frequentemente utilizado no tratamento de efluentes (Mota et al., 2005). O processo é seguro por utilizar íon 
ferroso que apresenta baixa toxicidade e peróxido de hidrogênio que em sua decomposição forma água e $\mathrm{O}_{2}$. O peróxido, na ausência de luz tem sua decomposição catalisada pelo íon ferroso, formando radicais hidroxila que degradarão o fármaco (Coelho et al., 2005). Neste trabalho o fármaco estudado foi a oxitetraciclina.

Reações que descrevem a degradação pelo processo Fenton:

$$
\begin{aligned}
& \mathrm{Fe}^{2+}+\mathrm{H}_{2} \mathrm{O}_{2} \rightarrow \mathrm{Fe}^{3+}+\mathrm{HO}-+\mathrm{HO} \cdot \\
& \mathrm{Fe}^{2+}+\mathrm{HO} \rightarrow \mathrm{Fe}^{3+}+\mathrm{HO}- \\
& \mathrm{RH}+\mathrm{HO} \cdot+\mathrm{H}_{2} \mathrm{O}^{+} \rightarrow \quad \text { Produtos oxidados } \\
& \mathrm{Fe}^{3+}+\mathrm{H}_{2} \mathrm{O}_{2} \rightarrow \mathrm{Fe} \mathrm{OOH}++\mathrm{H}^{+} \\
& \mathrm{Fe} \mathrm{OOH} \rightarrow \mathrm{HO}_{2} \cdot+\mathrm{Fe}^{2+} \\
& \mathrm{HO}_{2}+\mathrm{Fe}^{2+} \rightarrow \mathrm{HO}_{2}+\mathrm{Fe}^{3+}
\end{aligned}
$$

\section{Objetivos}

Este trabalho tem como objetivo geral, analisar a eficiência da degradação da oxitetraciclina de soluções aquosas por meio de reações oxidativas promovidas pelo processo Fenton e avaliar a influência de todas as variáveis envolvidas no processo, iniciando por temperatura e concentração inicial do fármaco, caracterizando a reação do ponto de vista cinético.

\section{Materiais e Métodos}

Os equipamentos utilizados durante os ensaios foram: banho termostatizado, balança semianalítica, espectrofotômetro, agitadores mecânicos, termopares, medidor de $\mathrm{pH}$, béqueres, balões volumétricos, filtros e buretas. Um esquema simplificado é indicado na Figura 2. Inicialmente, preparou-se uma solução de 100 ppm de oxitetraciclina. Em uma balança semi-analítica, foram pesados $25 \mathrm{mg}$ de oxitetraciclina e homogeneizados com $250 \mathrm{~mL}$ de água destilada, em um balão volumétrico. Transferia-se $200 \mathrm{~mL}$ dessa solução para um béquer (A) coberto por papel alumínio, a fim de evitar a incidência de luz UV. O béquer era imerso em um banho termostatizado (B), onde se podia controlar a temperatura entre $0^{\circ} \mathrm{C}$ a $100^{\circ} \mathrm{C}$. Era utilizado um termopar (D), a fim de verificar a real temperatura da solução ao longo da reação. A solução era homogeneizada por meio de um agitador mecânico (C). Uma vez atingido o valor desejado da temperatura, era adicionada a solução de sulfato ferroso e peróxido de hidrogênio. Esses volumes eram pré-estabelecidos. Assim que ambos os componentes eram adicionados, iniciava-se a cronometragem do tempo. Então, eram coletadas amostras em determinados intervalos de tempo. Com as amostras, era possível determinar quantitativamente a concentração do fármaco residual e de peróxido de hidrogênio no meio, por espectrofotometria e titulação, respectivamente.

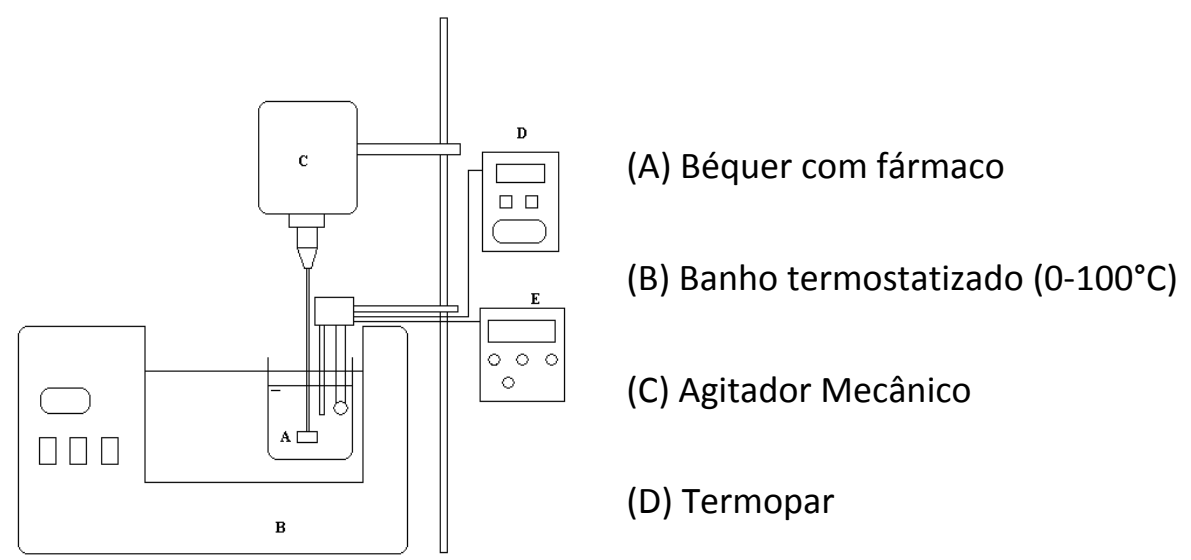

Figura 02 - Equipamento experimental para os ensaios de oxidação da oxitetraciclina por processo Fenton. 
Para determinação da concentração residual de oxitetraciclina e do peróxido de hidrogênio eram necessárias as seguintes soluções: Solução inibidora de sistema Foto-Fenton (dissolve-se $16,6 \mathrm{~g}$ de iodeto de potássio, $25,2 \mathrm{~g}$ de sulfito de sódio e $4 \mathrm{~g}$ de hidróxido de sódio, completando o volume de $1 \mathrm{~L}$ com água destilada); Solução de ácido sulfúrico 1:5 (em um balão de $1 \mathrm{~L}$, adiciona-se $200 \mathrm{ml}$ de ácido sulfúrico concentrado e completa-se o volume com água destilada); Solução de molibdato de sódio $5 \times 10^{-3} \mathrm{~mol}^{-L^{-1}}$ (dissolve-se $1,21 \mathrm{~g}$ de molibdato de sódio diidratado em balão volumétrico de $1 \mathrm{~L}$, completando o volume com água destilada); Solução de nitrato de sódio $1 \mathrm{~mol}^{-\mathrm{L}^{-1}}$ (dissolve-se $85 \mathrm{~g}$ de nitrato de sódio em balão volumétrico de $1 \mathrm{~L}$ e completa-se com água destilada); Solução tampão acetato $0,01 \mathrm{~mol}^{-\mathrm{L}^{-1}} \mathrm{pH} 5,0$ (dissolve-se $0,820 \mathrm{~g}$ de acetato de sódio anidro, $0,57 \mathrm{~mL}$ de ácido acético glacial em balão volumétrico de $1 \mathrm{~L}$, completando o volume com água destilada) (Morita e Assumpção, 1976). Para quantificar a oxitetraciclina residual (Stankov e Veselinovic, 1988), analisa-se, na verdade, o complexo formado entre a oxitetraciclina e o íon molibdato. Para isso, adicionava-se $2 \mathrm{~mL}$ da solução inibidora de sistema Foto-Fenton a $5 \mathrm{~mL}$ de amostra do meio, esta amostra era centrifugada para evitar interferência de íons ferro na leitura, $1 \mathrm{~mL}$ do sobrenadante era colocado em um balão de $5 \mathrm{~mL}$. Eram adicionados $1 \mathrm{~mL}$ de solução $\mathrm{Na}_{2} \mathrm{MoO}_{4} 5.10^{-3} \mathrm{~mol}^{-\mathrm{L}-}$ $1,0,5 \mathrm{~mL}$ de $\mathrm{NaNO}_{3} 1 \mathrm{~mol} . \mathrm{L}^{-1}$ e $0,5 \mathrm{~mL}$ de solução tampão acetato $0,01 \mathrm{~mol} . \mathrm{L}^{-1} \mathrm{pH} 5,0$ e completa-se o volume com água destilada. Essa solução era lida no espectrofotômetro com comprimento de onda $390 \mathrm{~nm}$. $O$ método espectrofotométrico baseia-se na lei de Beer-Lambert, onde a concentração é determinada por uma curva de calibração (Absorbância versus concentração de fármaco). Então era calculada a concentração de oxitetraciclina residual pela equação (7):

$\mathrm{C}_{\text {Oxi }}=\mathrm{K} . \mathrm{Abs}$

Onde: $C_{O x i}=$ Concentração de Oxitetraciclina residual (ppm)

Abs = Absorbância da amostra

$\mathrm{K}=$ Constante de proporcionalidade obtida por regressão linear.

\section{Resultados}

Os resultados de concentração residual de oxitetraciclina em função da temperatura e da concentração inicial do fármaco estão mostrados nas Figuras 3 e 4, respectivamente.

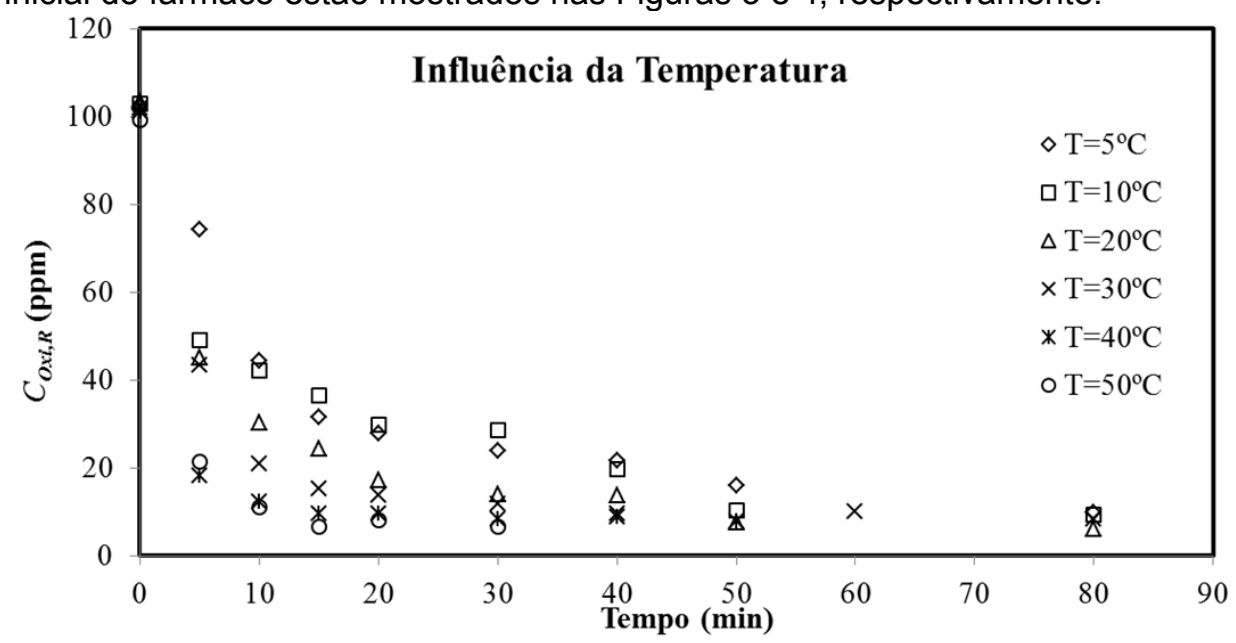

Figura 03 - Influência da temperatura na concentração residual de oxitetraciclina $\left(C_{O x i, R}\right)$ para concentração inicial de oxitetratciclina $C_{0}=100 \mathrm{ppm}, C_{\mathrm{Fe}^{2+}}=5 \mathrm{ppm}$ e $C_{\mathrm{H}_{202}}=100 \mathrm{ppm}$.

A Figura 3 mostra que a temperatura influencia significativamente o processo Fenton na faixa de valores estudada. Observa-se um nítido aumento da velocidade inicial da reação com o aumento da temperatura. No intervalo de 0 a $10 \mathrm{~min}$ a velocidade da reação foi de $5,8,6,1,7,3$, $8,1,8,9$ e $8,8 \mathrm{ppm} / \mathrm{min}$ para $T=5,10,20,3040$ e $50^{\circ} \mathrm{C}$, respectivamente. No entanto a concentração residual final do fármaco não teve variação significativa, que variou de 6,0 a 9,8 ppm. A Figura 4 mostra que a velocidade inicial de degradação do fármaco cresce com a concentração inicial do fármaco para temperaturas de até $20^{\circ} \mathrm{C}$. A concentração residual final normalizada do fármaco diminui com o aumento da temperatura. Também se pode observar que a concentração inicial do fármaco $\left(C_{0}\right)$ influencia mais o processo a baixas temperaturas e não e 
significativa pata $T=40^{\circ} \mathrm{C}$. Estes resultados demonstram que a constante da taxa da reação é bastante sensível à temperatura na faixa de valores estudada.

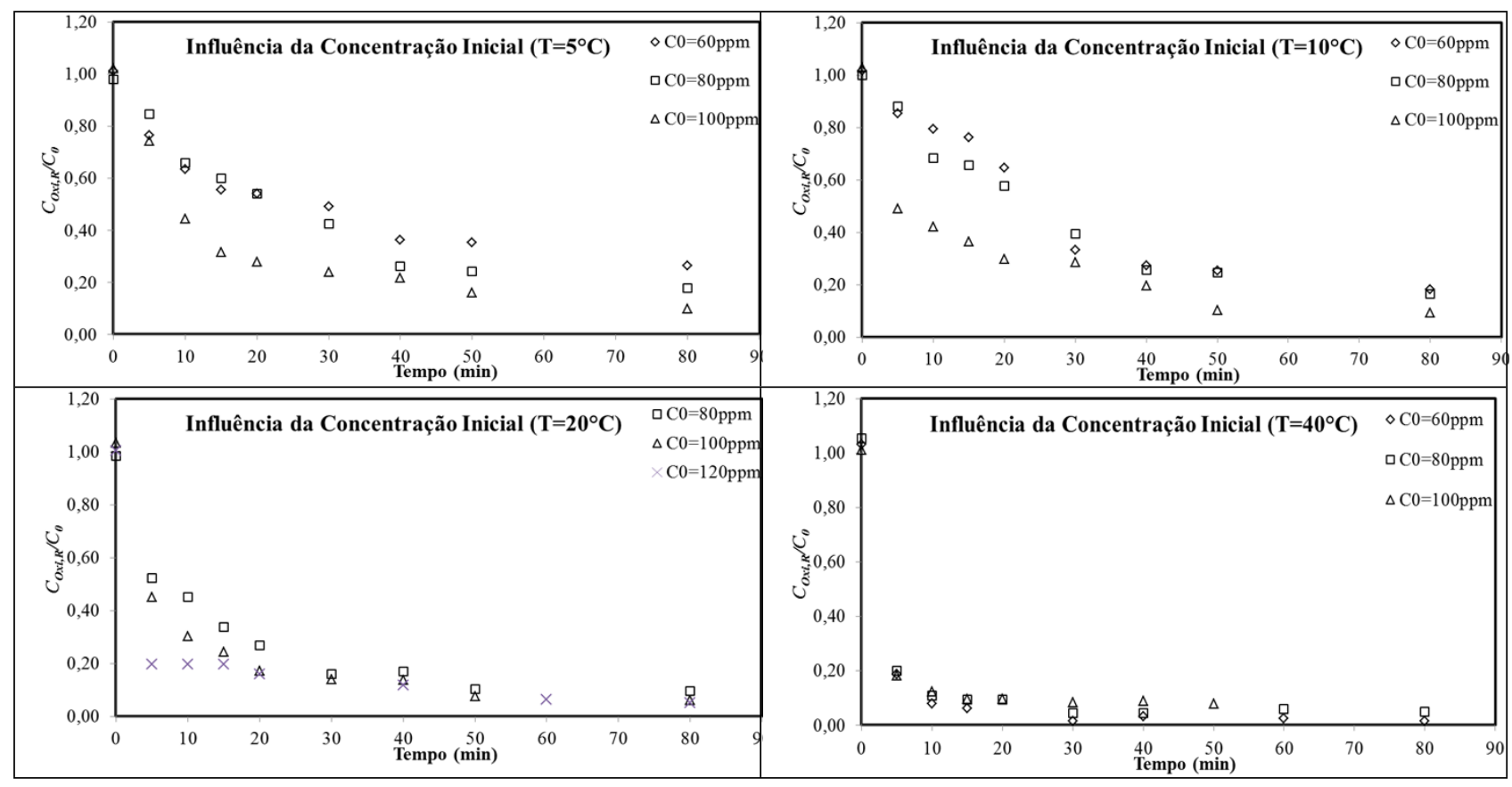

Figura 04 - Influência da concentração inicial de oxitetraciclina $\left(C_{0}\right)$ e da temperatura na concentração residual normalizada de oxitetraciclina $\left(C_{\mathrm{Oxi}, R} / C_{0}\right)$ para $C_{\mathrm{Fe}}{ }^{2+}=5 \mathrm{ppm}$ e $C_{\mathrm{H} 2 \mathrm{O} 2}=100 \mathrm{ppm}$.

\section{Conclusões}

O estudo teve como objetivo avaliar a influência das variáveis do processo Fenton na concentração residual final de oxitetraciclina, a fim de estudar a eficiência do processo em diversas condições e avaliar a possibilidade de aplicação em larga escala do processo, os resultados mostram que a alteração de variáveis da reação apenas influencia em sua cinética, ou seja, a velocidade da reação é a alteração mais notável, enquanto a concentração final do fármaco se mantém e a eficiência do processo ainda é mantida por volta dos $90 \%$. A análise mais interessante é a da variação de concentração inicial do fármaco, a eficiência também foi mantida neste estudo, mostrando assim que o processo oxidativo é muito favorável para degradação deste fármaco em amostras de efluentes possivelmente contaminadas com diferentes concentrações de oxitetraciclina.

\section{Referências Bibliográficas}

BORGHI, A.A. Degradação de cloridrato de doxiciclina pelo processo Fenton. Dissertação (mestrado) Faculdade de Ciências Farmacêuticas da Universidade de São Paulo, 169p., 2013.

COELHO, A.; CASTRO, A.V.; DEZOTTI, M. SANT'ANNA JUNIOR.; G.L. Tratamento das águas ácidas de refinaria de petróleo pelos processos Fenton e Foto-Fenton combinados. $23^{\circ}$ Congresso Brasileiro de Engenharia Sanitária e Ambiental, Campo Grande-MS. 2005.

MORITA, T.; ASSUMPÇÃO, R.M.V. Manual de soluções, reagentes e solventes. Ed. Edgard Blucher LTDA. $2^{\mathrm{a}}$ edição, 1976. p.106.

MOTA, A.L.N.; MURANAKA, C.T.; MORAES, J.E.F.; NASCIMENTO, C.A.O.; CHIAVONE-FILHO, O. Aplicação do processo Foto-Fenton na fotodegradação do fenol em meio aquoso utilizando lâmpadas de luz negra como fonte de radiação. XXI Congreso Interamericano de Ingeniería Química - Peru, 2005.

STANKOV, M.J.; VESELINOVIC, D. Spectrophotometric methods for determination of doxycycline in pharmaceutical preparations. Pharmazie, v.43, № 1, 1988. p. 49-50.

WATKINSON, A.J.; MURBYD, E.J.; KOLPING, D.W.; COSTANZO, S.D. The occurrence of antibiotics in an urban watershed: From wastewater to drinking water. Sci. Tot. Environ., v.407 (8), 2009.p.2711-2723. 